Institute of $\mathbf{F}_{\text {ood and }} \mathbf{A}_{\text {gricultural }} \mathbf{S}_{\text {ciences }}$

\title{
Proper Calibration of Soil Fumigant Application Equipment $^{1}$
}

J.W. Noling and J.P. Gilreath ${ }^{2}$

\section{Dosage and Field Application Rate}

Calibration of soil fumigant equipment and determination of application rate are two of the most important factors contributing to the success or failure of pest control efficacy and crop production response, but yet, generates some of the greatest confusion among many researchers and growers alike. Little confusion exists with the calculation or expression of broadcast or overall application rates when the entire field area is to receive fumigant treatment. The real confusion for many exists when the entire area of the field is not treated as with in-row fumigant applications. When in-row fumigant application rates are expressed as pounds or gallons per acre, it is not instantly clear whether the rate represents the amount of fumigant applied to that part of an acre actually under plastic and receiving an in-row fumigant treatment or to an actual acre of mulch covered, bedded row. Similar problems of interpretation can exist with terminology expressing dosage as fumigant product per gross, net, or plastic acre, or per so many rolls of plastic. For in-row or bedded applications, the generally accepted terminology is per treated acre, ie., the actual land area under plastic receiving fumigant treatment. For in-row applications in which dosage is expressed per treated acre, it is relating the area of treated land and not total cropland covered. Considering application rates as the broadcast equivalent per row acre of mulched covered bed may serve to help minimize such confusion. In this terminology, the broadcast rate is actually applied to the area treated, ie., the area under or delimited by the plastic. The diagram and description of Figure 1 may also help to clarify application rate terminology.

Once dosage or application rate is clearly defined, the next step in the calibration process is to determine how to dispense the fumigant within the treated area as the application equipment progresses through the field during application. Errors occurring at this stage of the calibration process can result in fumigant rates which are low and ineffective, or as over application, which are more costly, unnecessary, and potentially environmentally hazardous.

Factors other than dosage which are critical to the overall soil fumigant application process include

1. This document is ENY-047, one of a series of the Entomology \& Nematology Department, Florida Cooperative Extension Service, Institute of Food and Agricultural Sciences, University of Florida. Published: February 2002. For more publications related to horticulture/agriculture, please visit the EDIS Website at http://edis.ifas.ufl.edu/.

2. J. W. Noling, professor, Entomology and Nematology Department, Citrus Research and Education Center, Lake Alfred, FL 33850, and J. P. Gilreath, associate professor, Horticultural Sciences, Gulf Coast REC, Cooperative Extension Service, Institute of Food and Agricultural Sciences, University of Florida, Bradenton, FL 34203.

The Institute of Food and Agricultural Sciences is an equal opportunity/affirmative action employer authorized to provide research, educational information and other services only to individuals and institutions that function without regard to race, color, sex, age, handicap, or national origin. For information on obtaining other extension publications, contact your county Cooperative Extension Service office. Florida Cooperative Extension Service/Institute of Food and Agricultural Sciences/University of Florida/Christine Taylor Waddill, Dean. 


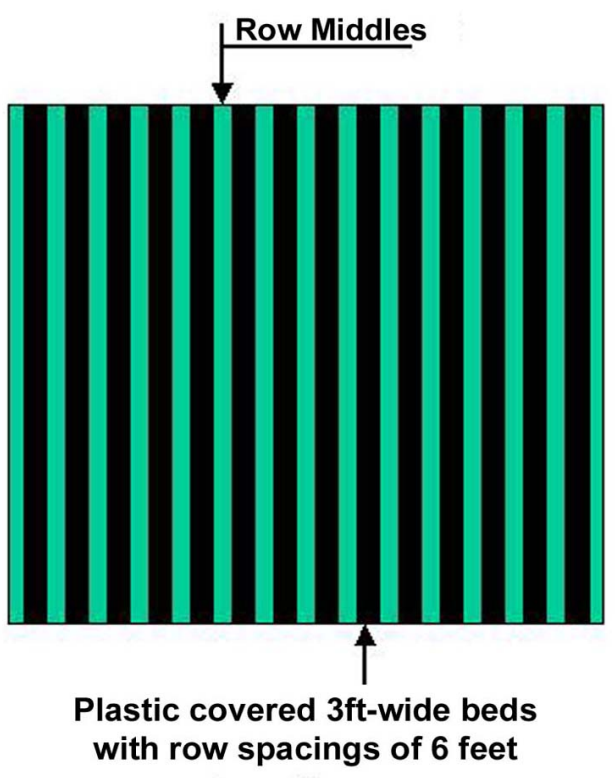

Figure 1. A vegetable field composed of plastic mulch covered rows and uncovered row middles in which tht total area of the block is 1 acre $(43,560 \mathrm{sq} f t)$ in size. If the plastic covered rows are 3 feet wide and the row spacing is 6 feet, then the filed area under plastic receiving fumigant treatment is actually only one half acre in size or 7,260 linear feet of row. Assuming a maximum broadcast application rate of $350 \mathrm{lb} / \mathrm{a}$, then only $50 \%$ of the acre will receive fumigant treatment, and the amount of fumigant applied within the block or acre of field is $175 \mathrm{lb} / \mathrm{a}$. The correct expression of application rate for this scenario is $175 \mathrm{lb} / \mathrm{a}$ and/or $350 \mathrm{lb} /$ treated acre. Treated acre meaning area of actually treated land and not cropland covered. The broadcast equivalent of this in-row application is also expressed as $350 \mathrm{lb} / \mathrm{a}$ or $350 \mathrm{lb}$ in 14,520 linear feet of row 3 feet wide.

determinations of treatment band or swath width, tractor speed, and flow meter calibration.

\section{Flow Meter Calibration}

All soil fumigants, like methyl bromide, chloropicrin, and 1,3-dichloropropene (Telone), are liquids under pressure, and volatilize to gases when exposed to the atmosphere. They are typically manufactured and distributed in pressurized cylinders. As an inert gas, nitrogen is used to maintain constant pressure to the fumigant cylinder to ensure a constant flow of the fumigant from the cylinder to the metering devise during application. In-line valves downstream of the fumigant cylinder are then used to actually control the delivery rate of the fumigant to and thru the flow meter.
For most soil fumigant metering systems, a tapered flow tube and float needle is used. The tapered flow tube is configured with a tapered throat leading to a tube constriction, while the exit from the constriction is smooth and elongated. As with any venturi or tapered flow tube, only so much liquid up to a maximum defined as $100 \%$ flow, can be forced through the constricted zone of the tube per unit time, regardless of pressure. The maximum or $100 \%$ flow rate of the fumigant liquid is therefore directly proportional to the cross-sectional area of the smallest passage within the flow meter.

Most of the fumigant flow meters available today are calibrated for water, and not fumigants. Different size flow meters are commercially available but most only allow a maximum $100 \%$ flow rate in the range of 1 to 3 gallons of water per minute. Regardless of size or discharge capacity, the sole function of the meter is to act as a simple gauge to indicate the percentage of maximum flow (0-100\%) discharging from the meter. For calibration purposes then, applicators must first know whether the flow meter is designed for water and the maximum $100 \%$ flow capacity of the meter. This information is usually placarded directed on the exterior housing or within the front window of the flow meter.

Factors other than flow tube size can effect a liquids actual flow rate through the meter. These factors include the liquids viscosity, density, and pipe friction. Friction and viscosity are drag forces reducing flow, and are typically small and inconsequential. Density of the fluid is its weight per unit volume, often expressed in units of pounds per gallon or grams per mil. For example, the density of water is $8.345 \mathrm{lb}$ per gallon (Table 1). As Table 1 illustrates, the density of the various fumigants used today in commercial agriculture are all considerably heavier than that of water, particularly that of methyl bromide and chloropicrin. All fumigants which are denser ie., heavier than water per unit volume will move through a flow meter more slowly than that of water. As a result, flow meters calibrated for water must be corrected to account for the reduced maximum $100 \%$ flow capacity of the meter for the heavier fumigant compounds. To determine the flow meter correction factor, applicators must know the 
density of the fumigant in order to calculate the fumigant's specific gravity. Information regarding the density or weight of the fumigant can be found in Table 1 or directly on the pesticide label on the fumigant container.

The specific gravity of a fumigant liquid is a ratio of the density of the liquid to the density of an equal volume of water. As a ratio of densities, it is a relative measure with no units associated with it. For example, the density of water is $8.345 \mathrm{lb}$ per gallon. If the density of methyl bromide is $14.4 \mathrm{lbs}$ per gallon, then the specific gravity of methyl bromide is 1.726 (Density $_{\mathrm{F}} /$ Density $_{\mathrm{W}}$; ie., 14.4 lb per gallon divided by 8.345$)$. Methyl bromide is a very dense liquid and is approximately $172.6 \%$ heavier than water. All soil fumigants have different densities (specific weights) and are heavier than water. In general, the denser a liquid is, the higher its specific gravity, and the more slowly it will flow through a flow meter compared to water. Because of the differences in specific gravity of the various agricultural fumigants, the capacity of the flow meter, typically expressed in gallons per minute, must be corrected according to Equation 1 where specific gravity is the density of the fumigant divided by the density of water. Figure 2 illustrates the actual flow meter correction factors for reduced $100 \%$ maximum flow capacity for various fumigants based on the specific gravity of the fumigant. All values are less than 1 indicating that maximum flow capacity is reduced. An example from figure 2 shows that the maximum $100 \%$ flow capacity of a flow meter calibrated for water is reduced by $28 \%$ (1.0 minus 0.72 ) when a heavier fluid such as methyl bromide is passed through the meter.

Equation 1: Calculation of a flow meter correction factor from water to a denser liquid.

\section{Correction Factor $=1 /$ square root of the specific gravity of the fumigant liquid}

Example problem: A certified applicator wants to apply 1,3-D using a flow meter calibrated for water. The $100 \%$ maximum flow rate of the meter for water is $2.43 \mathrm{gpm}$. What is a) the specific gravity of $1,3-\mathrm{D}, \mathrm{b}$ ) flow meter correction factor, and c) new $100 \%$ maximum flow capacity of the meter for the heavier 1,3-D.

$$
C F=\sqrt{S G_{F}}
$$

Solution: The density or weight of 1,3-D is $10.2 \mathrm{lb} / \mathrm{gal}$ and for water it is $8.345 \mathrm{lb} / \mathrm{gal}$. The specific gravity of $1,3-\mathrm{D}$ is $1.218(10.2$ / 8.345). The correction factor for $1,3-\mathrm{D}$ is calculated according to equation 1 as [ $1 /$ square root (1.218)]. The correction factor is 0.906 , meaning that the flow of $1,3-\mathrm{D}$ is 90.6 $\%$ of the maximum flow capacity of the meter for water $(2.43 \mathrm{gal} / \mathrm{min})$. The corrected $100 \%$ maximum flow capacity for $1,3-\mathrm{D}$ is therefore 2.20 gallons per minute $(0.906 \times 2.43)$.

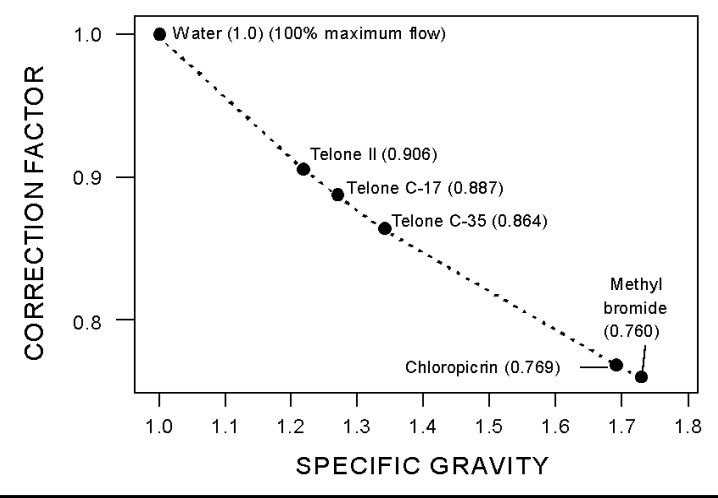

Figure 2. Flow meter correction factors for adjusting 100\% maximum flow rate capacity of a meter calibrated for water and applying a denser fumigant with a specific gravity greater than water.

In some instances, the fumigant flow meter in field use is already calibrated for measuring flow for a specific fumigant such as methyl bromide, and not water. When this is the case, the maximum $100 \%$ flow rate for the meter must first be converted from the fumigant it is calibrated for to water (use of equation 2), and then from water to the fumigant which is to be applied in the field (use of equation 1). The correction factor for adjusting the flow of a meter calibrated for a heavier fumigant liquid with a specific gravity greater than that of water is calculated according to Equation 2.

Equation 2: Calculation of a flow meter correction factor from a denser fumigant liquid to that of water. 


\section{Correction Factor $=$ Square Root of the Specific Gravity of the Fumigant Liquid;}

$$
C F=S G_{F}
$$

Example problem: A certified applicator wants to apply 1,3-D using a flow meter calibrated for methyl bromide. The $100 \%$ maximum flow rate of the meter for methyl bromide is $1.80 \mathrm{gpm}$. What is a) the correction factor for flow of methyl bromide to water; b) the $100 \%$ maximum flow capacity for water; c) the specific gravity of 1,3-D; d) flow meter correction factor for water to 1,3-D; and e) new $100 \%$ maximum flow capacity of the meter for the heavier 1,3-D.

Solution: The specific gravity of methyl bromide is 1.73 (14.4 / 8.345). The correction factor for methyl bromide to water according to equation 2 is 1.3153 (ie., the square root of 1.73). The corrected flow rate for water is 2.37 gpm $(1.3153 \times 1.8 \mathrm{gpm})$. The density or weight of 1,3-D is $10.2 \mathrm{lb} / \mathrm{gal}$ and for water it is $8.345 \mathrm{lb} / \mathrm{gal}$. The specific gravity of $1,3-\mathrm{D}$ is 1.218 ( 10.2 / 8.345). The correction factor for 1,3-D is calculated according to equation 1 as [ 1 / square root (1.218)]. The correction factor is 0.906 , meaning that the flow of $1,3-\mathrm{D}$ is $90.6 \%$ of the maximum flow capacity for water $(2.37 \mathrm{gal} / \mathrm{min})$. The corrected $100 \%$ maximum flow capacity for $1,3-\mathrm{D}$ is therefore 2.15 gallons per minute ( $0.906 \times 2.37)$.

\section{Tractor Speed Calibration}

Careful and precise assessment of tractor ground speed is also very important for accurate calibration of soil fumigant application in the field. If a tractor mounted radar systems is installed, ground speed determinations can be acquired directly from the radar unit. For fumigation equipment without radar, determination of ground speed requires a test course and a stop watch. For the test course, measure and flag a $100 \mathrm{ft}$ long interval in the field and record the time for the application equipment to travel the 100 linear feet. Insure that the test course reflects average soil conditions within the field. Repeat the process at least twice under actual in-field conditions, insuring identical transmission and tractor RPM settings, and tractor loads for all test runs. Average the travel times for all test runs. Tractor speed in miles per hour can then be calculated according to equation 3 :

\section{Equation 3:}

$$
\begin{gathered}
\text { Tractor Ground Speed }(M P H)= \\
\{(60 x 60 x \text { test course }) / \text { Seconds }\} / 5280 \\
\text { or }[68.2 / \text { Seconds }]
\end{gathered}
$$

\section{Treatment Width}

For broadcast applications where the entire land area is treated and plastic mulch is not used, the treated width is the product of the number of injection shanks or chisels times the distance between chisels. For in-row applications, this distance is the cumulative width of the number of beds simultaneously treated at the time of soil fumigation. For example, if a bed measures 3 feet wide at its base, and 3 beds are treated simultaneously, then treatment width is 9 feet. 


\section{REQUIRED INFORMATIOM FOR SOIL FUMIGANT CALIBRATION}

Seconds to Travel 100 feet

68.2 divide by Seconds

Broadcast Rate Per Acre or Per Treated Acre*

Treatment Width (under plastic)

Corrected Maximum 100\% Flow of Meter
$=$

$=$

$=$

$=$

$=$

lbs. / $\min$. seconds

$\mathrm{MPH}$

lbs. / acre

feet

\section{CALCULATION STEPS:}

Speed (mph x 88)

Ft. / min. x Treatment Width

Sq. ft. / min. divided by 43,560 sq. ft. / acre

Acre / min. x Broadcast Application / acre

Lbs. / min. divided by $100 \%$ flow of meter
$=$

$=$

$=$

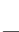

ft. / min.

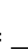
sq. ft. / $\min$. acres / $\min$. lbs. / $\min$. FLOW METER SETTING

* Ensure broadcast application rates in gallons per acre are properly converted to lbs/acre using the products density or specific weight (see Table 1).

Table 1.

\begin{tabular}{|c|c|c|c|}
\hline Fumigant & $\begin{array}{l}\text { Density } \\
\text { (lbs/gal) }\end{array}$ & Specific Gravity & $\begin{array}{c}\text { Conversion Factor } \\
\text { (100\% Flow Rate vs. Water) }\end{array}$ \\
\hline $\begin{array}{l}\text { Methyl Bromide } \\
(98 / 2) \\
\end{array}$ & 14.4 & 1.732 & 0.760 \\
\hline $\begin{array}{c}\text { Methyl Bromide } \\
(67 / 33) \\
\end{array}$ & 14.2 & 1.702 & 0.763 \\
\hline Telone II & 10.2 & 1.218 & 0.906 \\
\hline Telone C-17 & 10.6 & 1.27 & 0.887 \\
\hline Telone C-35 & 11.2 & 1.34 & 0.864 \\
\hline mulation ranrocant & & $\mathrm{n}$ by & \\
\hline
\end{tabular}

